\title{
ATITUDES ANTE PRODUTOS BANCÁRIOS: A VISÃO DOS FUNCIONÁRIOS
}

\section{ATTITUDES TOWARD BANK PRODUCTS: THE EMPLOYEE'S PERSPECTIVE}

MARCELO VINHAL NEPONUCENO Mestre em Psicologia pelo Instituto de Psicologia da Universidade de Brasília. Doutorando em Administração pela John Molson School of Business da Concordia University, Montreal, Canadá. SHIN QL 11, conjunto 4, casa 9, Lago Norte - Brasília - DF - CEP 71515-745 E-mail:marcelo_cripta@yahoo.com.br 


\section{RESUMO}

Esta pesquisa verifica a relação entre atitudes ante produtos bancários e variáveis sociodemográficas. Os produtos estudados foram: seguro de automóvel, seguro de vida, seguro residencial, previdência complementar, título de capitalização e consórcio imobiliário. As atitudes são consideradas um processo avaliativo de objetos, que gera uma avaliação positiva ou negativa, envolvendo três componentes (afetivo, cognitivo e conativo), sendo uma ligação entre dois conceitos. Os dados foram coletados juntamente aos funcionários de um grande banco nacional que vendem esses produtos e que se encontram nos pontos-de-venda. A pesquisa contou com 975 questionários válidos com respostas de quase todos os Estados. A escala desenvolvida para a pesquisa demonstrou confiabilidade após as análises fatoriais. Para testar as hipóteses, foram realizadas Regressões Stepwise que indicaram que idade, renda e principalmente gênero são variáveis relevantes para a atitude ante os produtos. Por fim, as contribuições e limitações da pesquisa são apresentadas.

\section{PALAVRAS-CHAVE}

Atitudes; Produtos bancários; Construção e validação de instrumento; Comportamento do consumidor; Psicologia do consumidor.

\section{ABSTRACT}

This research verifies the relation between attitudes toward bank products and social demographics variables. The products studied were: car insurance; life insurance; home insurance; retiring plan; capitalization heading; real state trust. The attitudes are considered as an evaluative process of objects, which generates a positive or negative evaluation, involving three components (affective, cognitive and conative), being a link between two concepts. The data was collected with employees of a large Brazilian bank who sell these products and are located in its point of sale. The research counted with 975 valid questionnaires with answers from almost all states. 
The measurement developed for this research has demonstrated high reliability after the factor analyses. To test the hypotheses Stepwise Regression were made which indicated that age, income and mainly gender are relevant variables for the attitude toward the products. Finally, the research contributions and limitations are presented.

\section{KEYWORDS}

Attitudes; Bank products; Measurement construction and validity; Consumer behaviour; Consumer psychology.

\section{ATITUdES ANTE PRODUTOS BANCÁRIOS}

A aquisição de produtos bancários é cada dia mais comum na população brasileira, principalmente após a estabilização econômica ocorrida nos últimos anos. Esse ambiente favorável tem estimulado uma maior concorrência entre as instituições financeiras, que buscam fidelizar seus clientes por meio da venda da maior quantidade possível de produtos. Essa estratégia baseia-se no argumento de que os clientes que possuem mais produtos com a instituição se desligariam mais dificilmente desta, visto que isso implicaria uma maior dificuldade de encontrar uma concorrente que pudesse suprir suas necessidades da mesma forma.

As informações quanto aos clientes, no entanto, não são de interesse exclusivo das instituições financeiras que vendem esses produtos. Órgãos reguladores, como o Banco Central, podem fazer uso dessas informações para regular o mercado de forma a padronizar regras mínimas de qualidade, visando à melhoria dos serviços prestados.

Os participantes desta pesquisa são empregados que vendem esses produtos. São eles que possuem contato direto com o cliente e percebem a maneira como este os avalia. Dessa maneira, conhecer suas opiniões é importante, pois não apenas está carregada das opiniões dos clientes, mas também pode auxiliar a explicar o sucesso ou insucesso de vendas, visto que uma atitude mais negativa ou positiva perante os produtos pode estar relacionada com sua dedicação, motivação e sucesso nas vendas.

Esta pesquisa busca compreender as atitudes desses funcionários com relação aos produtos bancários e ainda validar uma escala de atitudes para ser utili- 
zada em pesquisas futuras. Para alcançar tais objetivos, este artigo se organiza da seguinte maneira: inicialmente será discutido o conceito de atitudes e pesquisas relevantes na área; em seguira, serão apresentadas pesquisas relacionadas aos produtos estudados; posteriormente, apontam-se as hipóteses, os resultados e discussões de dois estudos que possibilitarão a confirmação destas.

\section{ATITUDE}

Historicamente, o conceito de atitude vem sendo definido por diversos autores. Tais definições por vezes são ambíguas, contraditórias e vagas. Em levantamento realizado por Allport (I935), cerca de uma centena de definições de atitudes foi encontrada até a década de I930.

Rodrigues (I972) e Fishbein (I966) postulam que as atitudes podem ser resumidas em três grandes componentes e/ou características: cognitivo, afetivo e conativo (ou comportamental). O componente cognitivo diz respeito à representação mental do objeto, que se relaciona às crenças, aos conhecimentos e a outras informações e adjetivos a respeito dele. O componente afetivo é definido como o sentimento pró ou contra um determinado objeto. Já o componente comportamental refere-se à intenção de se comportar perante o objeto, ou seja, a maneira que a pessoa espera ou deseja se comportar diante do objeto da atitude.

Petty (I995) afirma que as atitudes possuem apenas dois componentes e considera o componente conativo como um conceito separado. Ajzen e Fishbein (I980) demonstraram ainda uma definição unidimensional da atitude, na qual esta é entendida como uma quantidade de afeto, a favor de um objeto ou contra ele. Entretanto, na construção do instrumento desta pesquisa, foram encontrados itens que expressam a intenção de se comportar perante o objeto e outros que expressam crenças em relação a ele. Sendo assim, as atitudes são compreendidas conforme Rodrigues (I972) e Fishbein (I966) que apresentam três componentes.

As definições clássicas de atitude ainda são muito utilizadas atualmente. Os estudos mais recentes têm revelado um interesse maior em compreender as aplicações práticas da atitude em diferentes contextos. Estudos relativos à definição do conceito têm sido menos freqüentes. Como exemplo, o estudo de Cervellon e Dubé (2002) indica que os componentes afetivo e cognitivo da atitude são aplicáveis para várias culturas. O estudo foi realizado com participantes franceses, canadenses e chineses, e demonstrou que, mesmo para culturas diferentes, os componentes cognitivo e afetivo, aparentemente, funcionam da mesma maneira, sendo, portanto, distintos. 
No presente estudo, a atitude é compreendida como um processo Avaliativo de Objetos que gera uma avaliação negativa ou positiva envolvendo três componentes, sendo, portanto, uma ligação entre dois conceitos (FISHBEIN, I966; FAZIO et al., I986). A seguir essa definição será mais bem detalhada:

- $\quad$ Processo avaliativo de objetos..., pois as atitudes se referem a objetos, conceitos ou pessoas específicas com os quais os indivíduos entram em contato, direto ou indireto, durante a vida. No entanto, o simples contato com o objeto não implica uma atitude em relação a ele. Sendo assim, para que ocorra uma atitude, é necessário que haja uma avaliação em relação a esse objeto.

- ... que gera uma avaliação negativa ou positiva..., pois o processo levará a uma avaliação positiva ou negativa em relação ao objeto, resultando em uma atitude positiva ou negativa.

- ... envolvendo três componentes..., pois, conforme proposto por Fishbein (I966) e ilustrado anteriormente, as atitudes envolvem um componente afetivo (o que se sente sobre o objeto), cognitivo (o que se pensa sobre ele) e conativo (como se comporta diante dele).

- ... sendo, portanto uma ligação entre dois conceitos, visto que a atitude representa cognitivamente a ligação entre o objeto avaliado e sua avaliação propriamente dita.

Rodrigues (I972) aponta três importantes razões para o grande interesse na compreensão das atitudes, o que demonstra a importância do construto:

- Funcionam como preditores de comportamento. Por exemplo, o fato de uma pessoa ser favorável a um partido político ou ideal pode facilitar a predição do voto em uma eleição futura.

- Desempenham funções específicas, pois ajudam a criar uma idéia mais estável do mundo. Isso porque as atitudes funcionam como organizadoras (compiladoras) das informações que possuímos sobre os objetos com que entramos em contato, de maneira direta ou indireta. Essa organização resulta em uma atitude em relação a esse objeto.

- Funcionam como base para diversas situações sociais. As informações organizadas previamente influenciam as relações sociais futuras, principalmente porque as atitudes formadas exigem um gasto elevado para serem desconfirmadas. Com isso, o comportamento do indivíduo leva a confirmar as atitudes já preestabelecidas. 


\section{MENSURAÇÃO DAS ATITUDES}

As atitudes têm sido medidas de diversas maneiras, dependendo dos objetivos da pesquisa. Muitas vezes são medidas por meio de um único item, que mensura apenas uma de suas funções.

Maio e Olson (I995) mediram as funções das atitudes por meio da listagem de opiniões dos participantes em relação a um objeto. Após isso, os pesquisadores codificaram as opiniões de acordo com as funções que elas representavam. Já Gregory et al. (2002) criaram um instrumento em que os participantes avaliavam se aprovavam um anúncio, o produto, e se eram condizentes. Esse instrumento era respondido em três escalas semânticas de nove pontos, "Gosto a Não gosto", "Positivo a Negativo" e "Bom a Mal".

Um fator relevante para determinar a forma como a atitude é mensurada é a maneira como esta é compreendida. Para Fishbein e Ajzen (I975), a intenção de se comportar não faz parte do conceito de atitude, eles entendem que a atitude é uma quantidade de afeto pró ou contra um objeto ou situação. Segundo esses autores, a intenção de comportar é formada por dois fatores: as atitudes que o indivíduo possui em relação ao objeto e a percepção que ele possui das expectativas de terceiros, que lhe são significativos, sobre como deve proceder perante o objeto ou a situação. Este segundo fator os autores chamam de norma subjetiva.

Esse enfoque teórico de Fishbein e Ajzen (I975) é conhecido como Teoria da Ação Racional. Segundo essa teoria, a atitude de uma pessoa em relação a um objeto está relacionada com o conjunto de crenças relativas ao objeto e não necessariamente com uma crença específica. Da mesma forma, a relação entre atitudes e intenção de comportamento não é formada por uma única intenção comportamental, mas sim por um conjunto de intenções comportamentais.

A construção de um instrumento utilizando esse referencial inicia-se com a realização de entrevistas com o público-alvo, na qual os indivíduos são questionados quanto às avaliações que fazem sobre o objeto e as crenças que possuem relacionadas a ele. Em seguida, o questionário é construído considerando verbalizações mais freqüentes ou relevantes. Na avaliação das atitudes, deve-se indicar se ela é útil ou inútil, boa ou má e agradável ou desagradável. Na avaliação das crenças, os indivíduos devem responder considerando a probabilidade de cada uma acontecer e também avaliando se ela é boa ou má. Dessa maneira, é indicada a força dessa crença.

Outra teoria relevante para mensuração é a Diferencial Semântico, estudada por Osgood et al. ( 1967$)$. Segundo os autores, o significado de cada palavra ocupa um ponto no espaço semântico definido por adjetivos bipolares. Dessa maneira, 
eles procuram identificar os eixos que caracterizam o significado de conceitos utilizados. Essa caracterização foi realizada por meio de uma pesquisa que reconhece três dimensões ortogonais: fator avaliativo, que explica a maior parte da variância que pode ser exemplificado pelos opostos bom/mau, agradável/desagradável, alegre/triste etc.; um fator chamado de potência, exemplificado como rico/pobre, grande/pequeno, forte/fraco etc.; e um terceiro chamado de atividade, exemplificado como ativo/passivo, rápido/lento, quente/frio etc.

Essa técnica é interessante, pois permite constatar diferenças entre pessoas em relação a um mesmo objeto. As atitudes podem ser compreendidas como processos aprendidos e implícitos, potencialmente bipolares, que variam em direção e intensidade e que medeiam o comportamento avaliativo. Dessa forma, é coerente inferir que a atitude é parte da estrutura semântica de um indivíduo, podendo ser mensurada por meio de adjetivos bipolares.

Em resumo, verifica-se que não existe um padrão para mensuração das atitudes, inicialmente em razão da infinidade de objetos que podem ser avaliados, mas também pela grande quantidade de teorias existentes sobre o tema.

\section{PRODUTOS ESTUDADOS}

Os produtos estudados são relevantes não apenas para as instituições financeiras, mas ainda para os clientes, visto que estes os demandam cada vez em maior quantidade. Além disso, outro critério importante que influenciou na escolha desses produtos foi o fato de eles serem oferecidos pela instituição financeira na qual a pesquisa se realizou. A seguir, será feita uma breve apresentação sobre os seis produtos estudados.

Existem vários tipos de seguros oferecidos no mercado, no entanto nesta pesquisa serão considerados apenas três: de automóvel, de vida e residencial. Willcox e Harris (apud SEVERN, I986) demonstraram que as pessoas possuem uma atitude negativa diante de vendedores, e ainda mais negativa perante vendedores de seguros, definindo-os como menos confiáveis. Segundo os autores, isso pode explicar em parte a atitude negativa dos consumidores perante esse produto. Cato (2002) também constatou uma atitude negativa ante as seguradoras após entrevistar 700 americanos e demonstrar a desconfiança do público perante a indústria de seguros e as instituições financeiras. A enquete realizada com 25 setores da economia demonstra que o segmento menos confiável é o de óleo e gasolina, seguido por seguradoras e corretores da bolsa de valores.

Além dos seguros, três outros produtos foram estudados nesta pesquisa: previdência complementar, títulos de capitalização e consórcio imobiliário. 
No Brasil, a necessidade de adquirir previdência complementar cresceu recentemente. Segundo Marques et al. (2003), após a Constituição de I988, a Seguridade Social do Brasil passou a ser responsável pela proteção social para segmentos da sociedade que até então não haviam contribuído com o sistema. Além disso, o aumento do desemprego, ocorrido nos anos I980 e I990, contribuiu para elevação dos déficits, acarretando uma diminuição na arrecadação de contribuições sociais. Nesse cenário, o Brasil se viu obrigado a realizar constantes reformas na previdência com procedimentos semelhantes aos praticados em países desenvolvidos. Dessa forma, indiretamente houve um incentivo à contribuição a uma previdência social privada, para complementação dos salários dos futuros aposentados. Com isso, bancos, empresas e instituições financeiras têm oferecido produtos de previdência complementar.

Os títulos de capitalização são investimentos em que o cliente aplica mensalmente um valor, que é debitado de sua conta. Esse valor possui rendimento abaixo do mercado, no entanto o investidor concorre a prêmios mensais, anuais ou mesmo diários. $\mathrm{O}$ valor e a quantidade dos prêmios ocorrem apenas para aqueles que mantêm o pagamento atualizado. O consórcio é uma forma de empréstimo que é vinculado ao bem que se deseja adquirir, ou seja, é um empréstimo exclusivo para aquisição de um produto específico. No caso desta pesquisa, o bem vinculado é um imóvel. Neste empréstimo, as prestações e os juros são mais acessíveis, mas o imóvel não é obtido de imediato. Em datas predefinidas, ocorrem sorteios nos quais os contemplados recebem o imóvel no valor no qual o empréstimo foi feito. O recebimento do imóvel pode ser adiantado pelo pagamento de lances mensais maiores.

No caso do título de capitalização e consórcio imobiliário, o sorteio é relevante e característico do serviço oferecido pela instituição. Dessa forma, a atitude ante esses produtos provavelmente estará ligada à maneira como as pessoas lidam com o risco. Este argumento serviu como base para a criação das hipóteses relativas a esses produtos e que serão apresentadas a seguir.

\section{HIPÓTESES}

Uma vez que a pesquisa foi realizada a partir da avaliação de seis produtos distintos, as hipóteses serão apresentadas em separado. O Quadro I resume essas hipóteses, cujas justificativas são apresentadas a seguir com as pesquisas relevantes que embasaram sua criação. 


\section{QUADRO I}

\section{RESUMO DAS HIPÓTESES DO PRESENTE ESTUDO}

\begin{tabular}{lccc}
\hline & PREDIÇÃO NEGATIVA & NENHUMA RELAÇÃO & PREDIÇÃO POSITIVA \\
\hline Seguro de automóvel & Idade (H1) & - & Renda (H2) \\
\hline Seguro de vida & - & Renda, idade e gênero (H3) & $\begin{array}{c}\text { Quantidade de } \\
\text { filhos (H4) }\end{array}$ \\
\hline $\begin{array}{l}\text { Seguro residencial } \\
\text { Previdência }\end{array}$ & - & - & Renda (H5) \\
complementar & - & - & Idade (H6) \\
\hline Título de capitalização & Idade (H8) & - & Mulheres (H7) \\
\hline Consórcio imobiliário & Idade (H9) & - & - \\
\hline
\end{tabular}

Fonte: Elaborada pelo autor.

Quanto ao seguro de automóvel, levantaram-se as seguintes hipóteses:

- Hipótese $1(\mathrm{HI})$ : haverá uma predição negativa da idade perante a atitude em relação ao seguro de automóvel, visto que os resultados apresentados por Bond e Stone (2004) demonstram que pessoas mais velhas já passaram por mais experiências negativas com seguradoras ou ao menos já ouviram mais casos de amigos e pessoas próximas que passaram por dissabores. Essas experiências negativas farão, portanto, que a atitude seja mais negativa.

- Hipótese $2(\mathrm{H} 2)$ : haverá uma predição positiva de renda perante a atitude em relação ao seguro de automóvel, pois, conforme Bond e Stone (2004), optar por um carro reserva favorece uma avaliação positiva referente aos seguros de automóvel. Para tal é necessário possuir mais recursos financeiros para pagar por este e outros opcionais. Além disso, pessoas com renda mais baixa podem não possuir um automóvel ou ter um que não seja coberto pela maioria das seguradoras. Com isso tenderão a ter uma atitude mais negativa ante esse produto.

Quanto ao seguro de vida, foram levantadas as seguintes hipóteses:

- Hipótese $3\left(\mathrm{H}_{3}\right)$ : segundo estudo demonstrado por Greene (apud SEVERN, I986), a atitude perante o seguro de vida não está ligada a variáveis demo- 
gráficas (idade, gênero e renda). Espera-se, portanto, que seja encontrado o mesmo resultado de Greene.

- Hipótese $4\left(\mathrm{H}_{4}\right)$ : as pessoas que têm mais filhos apresentarão uma atitude mais positiva perante esse produto, visto que a preocupação com os entes queridos é um fator relevante para a aquisição deste.

Quanto ao seguro residencial, a seguinte hipótese foi levantada:

- Hipótese $5\left(\mathrm{H}_{5}\right)$ : haverá uma predição positiva de renda com a atitude em relação ao produto. Isso porque as pessoas de renda maior tenderão a residir em uma área ou imóvel que é mais visado por ladrões, portanto tendem a avaliar esse produto de maneira mais positiva.

Quanto à previdência complementar, as seguintes hipóteses foram levantadas:

- Hipótese 6 (H6): haverá uma predição positiva da idade ante a atitude em relação à previdência complementar. É esperado que pessoas mais velhas tenham a tendência de avaliar planos de aposentadoria de maneira mais positiva, porque o assunto é uma realidade próxima dessa população, conforme apontado por Murrel (I996).

- Hipótese $7\left(\mathrm{H}_{7}\right)$ : o gênero predirá significativamente a atitude perante a previdência complementar, e as mulheres possuirão uma atitude superior. Isso acontece porque elas tendem a aposentar-se antes dos homens e viver por um período maior de tempo, o que as torna ainda mais dependentes de planos de aposentadoria. Além disso, conforme Joo e Grable (200I), as mulheres procuram mais auxílio profissional, informando-se mais sobre o produto, o que, por sua vez, gera uma atitude mais positiva.

Quanto ao título de capitalização, a seguinte hipótese foi levantada:

- Hipótese 8 (H8): haverá uma predição negativa da idade ante a atitude em relação ao título de capitalização. Machauer e Morgner (200I) demonstraram que a atitude dos consumidores perante o risco é mais negativa para aqueles que têm uma idade mais elevada. Uma vez que os sorteios são percebidos como um evento de risco e ainda porque os títulos de capitalização proporcionam um rendimento menor do que outros investimentos de risco, é coerente imaginar que clientes que evitam o risco terão uma atitude mais negativa. 
Quanto ao consórcio imobiliário, levantou-se a seguinte hipótese:

- Hipótese 9 (H9): haverá uma predição negativa da idade em relação à atitude ante consórcio imobiliário em razão dos mesmos motivos apontados em H8. Essa diferença pode ser ainda maior, pois há uma tendência das pessoas mais velhas de avaliarem o produto de maneira mais negativa, uma vez que a demora do sorteio passa a ser menos tolerável por aqueles que têm idade mais elevada, ao perceberem que têm menos tempo disponível para esperar.

A seguir, será apresentado o método adotado na pesquisa que contribuiu para testar as hipóteses apresentadas. Será descrito como o instrumento de atitudes foi desenvolvido, assim como a condução dos estudos i e 2. No estudo I, objetivou-se reduzir o instrumento após a realização de um estudo-piloto, estimando sua validade e confiabilidade. O estudo 2 aprofunda os objetivos do estudo I e realiza análises para verificar as hipóteses.

\section{DESENVOLVIMENTO DA ESCALA E ESTUDO 1}

O instrumento desenvolvido foi criado com base em entrevistas semi-estruturadas feitas com profissionais da área e com potenciais clientes dos produtos. Nessas entrevistas, eram coletadas as opiniões dos participantes a respeito dos produtos, que serviram de base para a redação dos itens do instrumento. As entrevistas deram origem a 22 itens gerais, com redação única para todos os produtos. Dessa forma, foi possível desenvolver um único instrumento para todos os seis produtos, avaliando-os em uma única página e escala. Esses itens foram avaliados em uma escala tipo Likert de cinco pontos, que variava de "Discordo totalmente" a "Concordo totalmente". No Apêndice I, é possível ver essa primeira versão do instrumento.

Essa primeira versão foi aplicada no estudo-piloto, em uma pequena amostra que visava excluir os itens que contribuíam pouco para mensuração do construto. Essa etapa contou com 93 participantes, sendo eles empregados de uma instituição financeira e clientes que já possuíam contato com os produtos. Dentre esses participantes, 6I,5\% são do sexo feminino e a média de idade foi de 34,79 anos $(\mathrm{dp}=9,58)$.

Os resultados encontrados foram submetidos à análise fatorial pelo método de componentes principais. Uma vez que a maioria dos itens possuía redação positiva, aqueles com redações negativas foram recodificados pelo inverso. Ou 
seja, as respostas que indicavam "Concordo totalmente" foram transformadas em "Discordo totalmente" e vice-versa. Com isso, as respostas foram transformadas para o oposto do que eram originalmente.

Foram realizadas seis análises fatoriais, uma para cada produto. Quando considerado eigenvalues superiores a I, foram encontrados entre três e cinco fatores para a atitude perante os produtos. Nessa primeira análise, excluíram-se os itens que possuíam carga fatorial inferior a 0,55 e que não apresentavam tal escore para pelo menos quatro produtos. Além disso, foram desconsiderados os fatores que eram compostos por apenas um item. Dessa maneira, seis itens foram excluídos e constatou-se que para todos os produtos a atitude deveria ser mensurada por apenas uma dimensão. Os itens 7, IO, I2, I5, I6 e I8 apresentados no Apêndice foram excluídos nessa etapa.

\section{ESTUDO 2}

A coleta de dados do estudo 2 foi realizada com auxílio de uma instituição financeira de porte nacional. Os participantes eram funcionários dessa empresa, trabalhavam em seus pontos-de-venda e tinham entre suas atribuições diárias a venda dos produtos estudados nesta pesquisa. Dessa forma, os participantes são indivíduos que possuem grande conhecimento quanto a esses produtos. Além disso, são pessoas que entram em contato com seus usuários finais, podendo ter uma percepção influenciada pelas reclamações e pelos elogios que escutam dos clientes.

Os i6 itens remanescentes foram aplicados em uma amostra de I.06I participantes, juntamente com outras perguntas de interesse da organização e variáveis não-analisadas neste artigo. A coleta ocorreu com auxílio de consultores que se encontravam em todos os Estados da Federação. Esses consultores estabeleciam grande contato com os pontos-de-venda e funcionários da instituição financeira e, por isso, tinham um envolvimento prévio com eles. Além disso, os próprios consultores tinham interesse na realização da pesquisa, pois desejavam entender como os seus vendedores percebem os produtos que vendem.

A amostra foi reduzida para 975 participantes, após a exclusão de questionários incompletos: 47,1\% são do sexo feminino e I, $6 \%$ não indicaram o gênero. A maioria dos participantes $(50,4 \%)$ possui ensino superior completo. A média de idade foi de 35,95 anos $(\mathrm{dp}=8,86)$. A maioria dos participantes possuía renda familiar entre $\mathrm{R} \$ 2.500,00$ e $\mathrm{R} \$ 4.000,00$ (26,2\%), e apenas $8,8 \%$ encontravam-se na faixa mais baixa de renda, entre R\$ I.000,00 e R I.500,00. A Região Sudeste foi a mais bem representada, com 49,7\% da amostra, enquanto a Região Norte obteve apenas $2,4 \%$ da amostra. 
Antes de realizar as análises para testar as hipóteses do presente estudo, fazse necessário realizar novas análises fatoriais do instrumento, para confirmar sua validade. Para tal, a amostra foi dividida aleatoriamente em três grupos. $\mathrm{O}$ primeiro foi composto por 325 sujeitos, e novamente se realizou uma análise utilizando o método de componentes principais. No segundo grupo, foi realizada uma análise fatorial exploratória com rotação Varimax, que contém 325 sujeitos. Por fim, realizou-se uma análise fatorial confirmatória com os 325 sujeitos restantes. Em cada uma dessas etapas, foram realizadas seis análises, uma para cada produto. Dessa maneira, objetivou-se validar o instrumento, tornando-o mais enxuto e objetivo possível. Uma vez definida a versão final do instrumento, foram feitas análises para testar as hipóteses propostas.

\subsection{ANÁLISE DE COMPONENTES PRINCIPAIS}

Realizaram-se seis análises de componentes principais, uma para cada produto. Quando considerado eigenvalues superiores a I, foram encontrados dois ou três fatores para a atitude perante os produtos. Excluíram-se os itens que apresentavam carga fatorial inferior a 0,5 e que não tinham tal escore para pelo menos quatro produtos. Além disso, foram desconsiderados os fatores que eram compostos por apenas um item. Isso resultou na exclusão de 2 itens (itens $9 \mathrm{e}$ I9 apresentados no Apêndice), que foram desconsiderados na análise seguinte. Esses itens possuem redação que mede a atitude ante os produtos de maneira muito indireta. No item não se questiona o participante sobre a atitude em si, mas sim como é a pessoa que compra ou a empresa que vende esse produto, sendo uma medida indireta do construto. Provavelmente por isso, eles tiveram carga fatorial menor e foram excluídos das análises. É interessante notar ainda que os itens que compõem o segundo fator possuem o mesmo tipo de limitação, e isso talvez ajude a explicar os resultados encontrados na análise seguinte.

\subsection{ANÁLISE FATORIAL EXPLORATÓRIA}

Foram realizadas seis análises fatoriais exploratórias, uma para cada produto, com o intuito de deixar o instrumento ainda mais limpo e confiável. A extração dos fatores se deu pelo método maximum likelihood com rotação Varimax. Quando considerados eigenvalues superiores a I, novamente foram encontrados dois ou três fatores para a atitude perante os produtos. Excluíram-se os itens que apresentavam carga fatorial inferior a 0,65 e que não tinham tal escore para pelo menos quatro produtos. Além disso, foram desconsiderados os fatores que eram compostos por apenas um item. Dessa maneira, a atitude perante todos os 
produtos foi composta por dois fatores. Esse procedimento resultou na exclusão dos itens 4, II e 2I, que foram desconsiderados na análise seguinte. Novamente, esses itens avaliaram os produtos de maneira indireta e por isso foram mais mal compreendidos pelos participantes, resultando em sua exclusão.

Como pode ser visto na Tabela 2 , dois fatores foram extraídos para todos os produtos. $\mathrm{O}$ fator I pode ser interpretado como atitude perante o produto, medida de forma direta, e o fator 2 pode ser interpretado como medida indireta da atitude ante os produtos. O fator 2 está composto por apenas dois itens (I4 e 22), o que piora consideravelmente seus índices de confiabilidade. Além disso, pelo fato de mensurarem a atitude de forma indireta, esses itens também foram desconsiderados para a análise seguinte, já que o objetivo desta pesquisa é mensurar as atitudes de maneira mais objetiva e limpa possível. Um instrumento com menos itens é ainda mais indicado, visto que reduz o esforço ao responder o questionário. Dessa forma, na análise fatorial confirmatória, será verificado se a solução do instrumento com apenas nove itens é adequada. Além disso, o instrumento possui um cunho generalista, já que mensura vários produtos em uma mesma medida. Torná-lo mais limpo e confiável pode favorecer sua aplicação em outros contextos e realidades.

Conforme pode ser visto na Tabela I, apenas um item possuiu carga fatorial mínima para o seguro de automóvel. Dessa forma, para esse produto a análise fatorial confirmatória contará com os nove itens remanescentes (itens I, 2, 3, 5 , 6,8 , I3, I7 e 20) como pertencentes ao fator I, resultado que ocorreu na análise de componentes principais. 


\section{TABELA I}

\begin{tabular}{|c|c|c|c|c|c|c|}
\hline & $\mathrm{AN}$ & $\begin{array}{l}\text { RESUMO I } \\
\text { ÁLISE FA' }\end{array}$ & $\begin{array}{l}\text { DOS RESU } \\
\text { TORIAL EY }\end{array}$ & $\begin{array}{l}\text { LTADOS I } \\
\text { XPLORATĆ }\end{array}$ & $\begin{array}{l}\text { DA } \\
\text { ÓRIA }\end{array}$ & \\
\hline & $\begin{array}{l}\text { SEGURO DE } \\
\text { VIDA }\end{array}$ & $\begin{array}{c}\text { SEGURO DE } \\
\text { AUTOMÓVEL }\end{array}$ & $\begin{array}{c}\text { SEGURO } \\
\text { RESIDENCIAL }\end{array}$ & $\begin{array}{c}\text { PREVIDÊNCIA } \\
\text { COMPLEMEN- } \\
\text { TAR }\end{array}$ & $\begin{array}{l}\text { TíTULOS DE } \\
\text { CAPITALIZA- } \\
\text { ÇÃO }\end{array}$ & $\begin{array}{l}\text { CONSÓRCIO } \\
\text { IMOBILIÁRIO }\end{array}$ \\
\hline & $\begin{array}{cc}\text { FATOR } & \text { FATOR } \\
1 & 2\end{array}$ & $\begin{array}{cc}\text { FATOR } & \text { FATOR } \\
1 & 2\end{array}$ & $\begin{array}{cc}\text { FATOR } & \text { FATOR } \\
1 & 2\end{array}$ & $\begin{array}{cc}\text { FATOR } & \text { FATOR } \\
1 & 2\end{array}$ & $\begin{array}{cc}\text { FATOR } & \text { FATOR } \\
1 & 2\end{array}$ & $\begin{array}{cc}\text { FATOR } & \text { FATOR } \\
1 & 2\end{array}$ \\
\hline Item 1 & 0,70 & & 0,72 & 0,71 & 0,69 & 0,73 \\
\hline Item 2 & 0,73 & & 0,68 & 0,77 & 0,77 & 0,78 \\
\hline Item 3 & 0,70 & & 0,73 & 0,71 & 0,81 & 0,76 \\
\hline Item 4 & & & & & 0,77 & 0,70 \\
\hline Item 5 & 0,71 & & 0,75 & 0,70 & 0,79 & 0,71 \\
\hline Item 6 & & 0,73 & & 0,71 & 0,77 & 0,77 \\
\hline Item 8 & 0,70 & & 0,75 & 0,68 & 0,82 & 0,70 \\
\hline Item 11 & 0,66 & & 0,66 & & 0,74 & \\
\hline Item 13 & 0,65 & & 0,69 & & 0,72 & 0,73 \\
\hline Item 14 & 0,77 & & 0,72 & & 0,77 & 0,69 \\
\hline Item 17 & & & 0,67 & 0,67 & 0,71 & \\
\hline Item 20 & 0,74 & & 0,77 & 0,74 & 0,74 & 0,77 \\
\hline Item 21 & & & 0,67 & & 0,67 & 0,74 \\
\hline Item 22 & & & 0,68 & 0,76 & 0,76 & 0,67 \\
\hline $\begin{array}{l}\text { Var. } \\
\text { explicada }\end{array}$ & $50,38 \%$ & $29,71 \%$ & $52,58 \%$ & $49,88 \%$ & $63,73 \%$ & $53,84 \%$ \\
\hline KMO & 0,913 & 0,873 & 0,922 & 0,91 & 0,943 & 0,911 \\
\hline
\end{tabular}

Fonte: Dados coletados na pesquisa. 


\subsection{ANÁLISE FATORIAL CONFIRMATÓRIA}

Finalmente, com os nove itens restantes foram realizadas análises fatoriais confirmatórias para a última apreciação do instrumento. Realizaram-se seis análises, uma para cada produto. A Tabela 2 apresenta o resumo dessas análises com o alfa de Cronbach e o GFI de cada instrumento. Vale ressaltar que para o cálculo do alfa de Cronbach foram considerados todos os 975 participantes e não apenas uma amostra aleatória. Os alfas obtidos foram bastante confiáveis, variando de 0,87 até 0,94 . Os índices GFI também foram apropriados (acima de 0,9), com exceção do consórcio imobiliário que obteve valor de 0,86 , mas ainda assim se mostrou confiável. Vale ressaltar que a exclusão de qualquer um dos itens para todos os produtos levaria a uma piora no alfa de Cronbach e no GFI do instrumento, demonstrando que o modelo com nove itens encontra-se apropriado. Soluções com dois ou mais fatores também não levavam a uma melhoria no modelo.

TABELA 2

CARGAS FATORIAIS, ALFA DE CRONBACH E GFI DE CADA PRODUTO

\begin{tabular}{|c|c|c|c|c|c|c|}
\hline & $\begin{array}{l}\text { SEGURO DE } \\
\text { VIDA }\end{array}$ & $\begin{array}{l}\text { SEGURO DE } \\
\text { AUTOMÓVEL }\end{array}$ & $\begin{array}{c}\text { SEGURO } \\
\text { RESIDENCIAL }\end{array}$ & $\begin{array}{l}\text { PREVIDÊNCIA } \\
\text { COMPLEMENTAR }\end{array}$ & $\begin{array}{c}\text { TíTULOS DE } \\
\text { CAPITALIZAÇÃO }\end{array}$ & $\begin{array}{l}\text { CONSÓRCIO } \\
\text { IMOBILIÁRIO }\end{array}$ \\
\hline & FATOR 1 & FATOR 1 & FATOR 1 & FATOR 1 & FATOR 1 & FATOR 1 \\
\hline Item 1 & 0,69 & 0,51 & 0,69 & 0,58 & 0,76 & 0,73 \\
\hline Item 2 & 0,81 & 0,68 & 0,79 & 0,75 & 0,82 & 0,78 \\
\hline Item 3 & 0,82 & 0,74 & 0,83 & 0,84 & 0,83 & 0,78 \\
\hline Item 5 & 0,80 & 0,67 & 0,76 & 0,76 & 0,80 & 0,72 \\
\hline Item 6 & 0,65 & 0,53 & 0,63 & 0,77 & 0,81 & 0,71 \\
\hline Item 8 & 0,76 & 0,73 & 0,76 & 0,79 & 0,87 & 0,71 \\
\hline Item 13 & 0,70 & 0,60 & 0,72 & 0,65 & 0,76 & 0,72 \\
\hline Item 17 & 0,76 & 0,72 & 0,73 & 0,76 & 0,75 & 0,62 \\
\hline Item 20 & 0,82 & 0,65 & 0,79 & 0,71 & 0,78 & 0,77 \\
\hline $\begin{array}{l}\text { Alfa de } \\
\text { Cronbach }\end{array}$ & 0,92 & 0,87 & 0,92 & 0,91 & 0,94 & 0,91 \\
\hline GFI & 0,91 & 0,92 & 0,92 & 0,93 & 0,91 & 0,86 \\
\hline
\end{tabular}

Fonte: Dados coletados na pesquisa. 
Todos os escores apresentados anteriormente demonstram que o instrumento é adequado para o teste das hipóteses já listadas. Dessa forma, a versão com nove itens é a utilizada para tal finalidade. A seção seguinte apresentará os resultados obtidos no estudo 2 e que possibilitarão discutir as hipóteses propostas.

\section{RESULTADOS DO ESTUDO 2}

Nesta seção, serão apresentados os resultados das seis regressões múltiplas realizadas, uma para cada produto. Foram realizadas regressões Stepwise, tendo como variável dependente a atitude perante cada um dos produtos e como variável independente os dados demográficos (idade, gênero, renda, escolaridade e quantidade de filhos). Optou-se pela análise Stepwise por causa da pequena quantidade de pesquisas sobre a atitude dos produtos estudados. Há um grande número de pesquisas que trata da relação entre os dados demográficos e esses produtos. No entanto, não foram encontradas pesquisas sobre a atitude propriamente dita. Dessa forma, considerou-se a análise Stepwise mais adequada, visto que é um método que não pressupõe conhecimento prévio, constatando a relação essencialmente estatística entre as variáveis.

A Tabela 3 apresenta os resultados das regressões. Quando se consideraram a atitude ante o seguro de automóvel como variável dependente e os dados demográficos como variáveis independentes, observou-se uma predição significativa de idade, renda e gênero. Quando se considerou a atitude ante o seguro de vida como variável dependente, as variáveis relevantes foram quantidade de filhos e gênero. Com relação à atitude ante seguro residencial, idade e gênero foram variáveis relevantes.

A atitude ante a previdência complementar teve apenas gênero como preditor relevante. A atitude perante os títulos de capitalização foi predita por renda e gênero. Por fim, é possível verificar que idade, escolaridade e gênero predisseram de maneira significativa a atitude ante o consórcio imobiliário. 
TABELA 3

RESULTADOS DAS REGRESSÕES

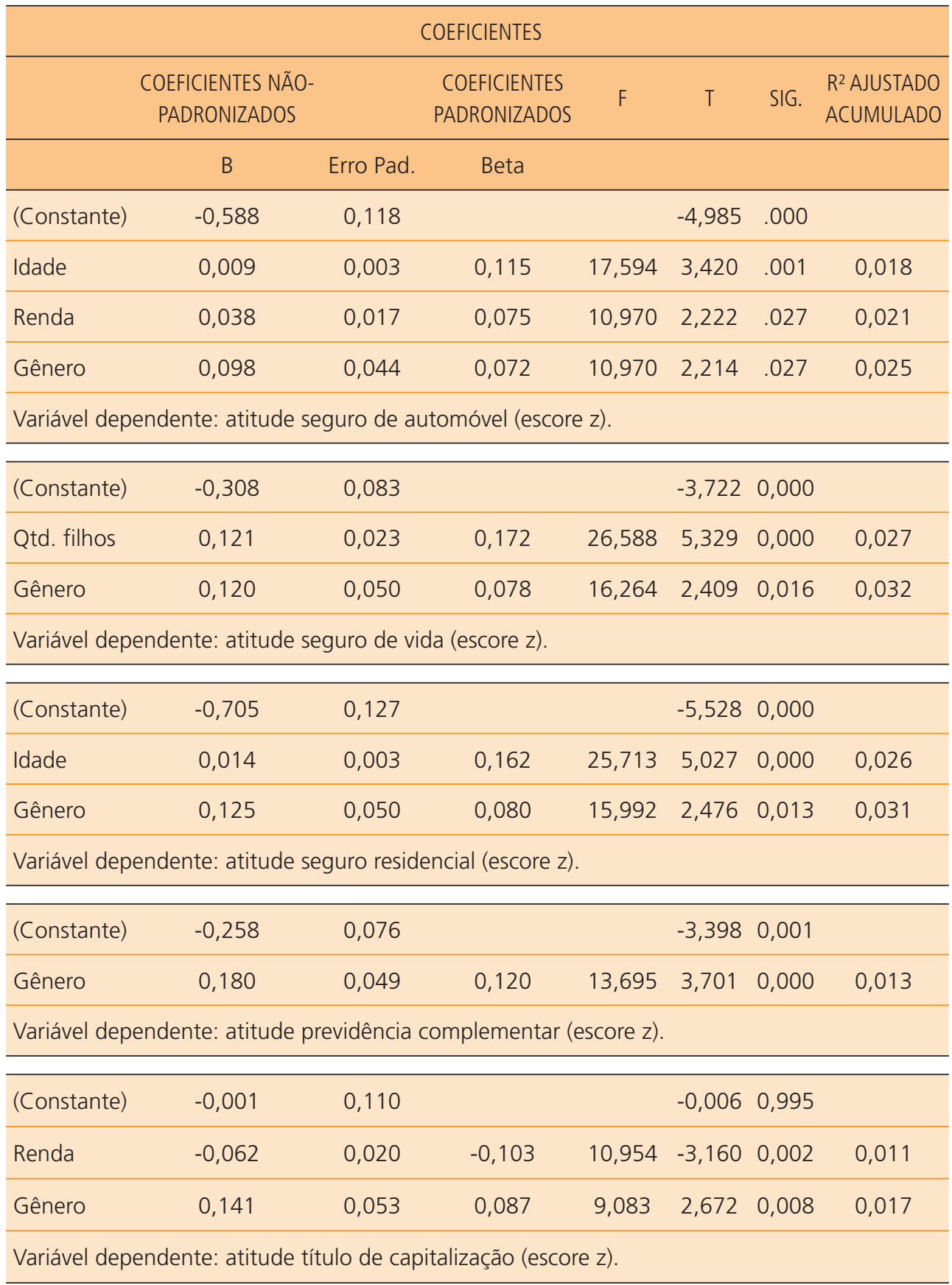


TABELA 3 (CONTINUAÇÃO)

RESULTADOS DAS REGRESSÕES

\begin{tabular}{|c|c|c|c|c|c|c|c|}
\hline \multicolumn{8}{|c|}{ COEFICIENTES } \\
\hline & $\begin{array}{c}\text { COEFICIENTES NÃO- } \\
\text { PADRONIZADOS }\end{array}$ & & $\begin{array}{l}\text { COEFICIENTES } \\
\text { PADRONIZADOS }\end{array}$ & $\mathrm{F}$ & T & SIG. & $\begin{array}{l}R^{2} \text { AJUSTADO } \\
\text { ACUMULADO }\end{array}$ \\
\hline & B & Erro Pad. & Beta & & & & \\
\hline (Constante) & 0,398 & 0,141 & & & 2,819 & 0,005 & \\
\hline Idade & $-0,009$ & 0,003 & $-0,109$ & 15,079 & $-3,227$ & 0,001 & 0,015 \\
\hline Escolaridade & $-0,074$ & 0,032 & $-0,078$ & 10,177 & $-2,327$ & 0,020 & 0,020 \\
\hline Gênero & 0,101 & 0,050 & 0,067 & 8,202 & 2,045 & 0,041 & 0,023 \\
\hline
\end{tabular}

Fonte: Dados coletados na pesquisa.

Duas importantes ressalvas devem ser feitas com relação a esses resultados para que eles sejam bem compreendidos. Em primeiro lugar, no caso desta pesquisa, uma relação significativa com beta positivo com relação ao gênero, indica que a atitude está relacionada ao sexo feminino, ou seja, a atitude é maior para as mulheres.

A segunda ressalva é relativa aos $\mathrm{R}^{2}$ ajustados que se apresentam muito baixos para todos os produtos. Isso provavelmente é decorrente da restrição de amplitude gerada pela forma como os dados foram mensurados. Essa restrição ocorre quando os escores obtidos na amostra são menores do que os escores da população real, diminuindo a mensuração da correlação entre as variáveis Whitley (200I). Isso ocorreu com a variável renda que foi respondida de forma categórica, mas considerada uma variável intervalar para as análises de regressão. Esse achatamento dos valores reais da variável faz com que as correlações por ela mensuradas sejam menores. Processo semelhante ocorre com a variável gênero que, por ser dicotômica, naturalmente possuirá importância menor em uma análise de regressão linear.

\section{DISCUSSÃO}

Nove hipóteses foram levantadas e serão consideradas nesta seção. Além disso, também serão discutidos os resultados encontrados e que não foram previstos, para que assim possam ser mais bem compreendidos. 
Os resultados obtidos com relação ao seguro de automóvel demonstraram um pensamento diferente do inicialmente pensado para a primeira hipótese. Para Bond e Stone (2004), pessoas mais velhas possuem uma atitude mais negativa, com a tendência de terem tido mais contato com o seguro de automóvel e com maior chance de terem passado por uma experiência negativa. Além disso, possuem maior chance de terem ouvido falar de casos negativos vivenciados por amigos. Esta pesquisa demonstra que no público brasileiro a lógica é inversa. $\mathrm{O}$ resultado indica que pessoas com idade superior tendem a possuir uma renda maior e com isso maior chance de terem um automóvel, sendo, portanto, um público que tem maior necessidade do produto, principalmente se considerarmos a elevada percepção de risco ao possuir um automóvel, ao levarmos em conta a quantidade de furtos e acidentes de trânsito no Brasil. Além disso, indivíduos mais velhos tendem a ser mais conservadores (Schwartz, 2005) e por isso tendem a perceber o seguro de uma maneira mais positiva. Dessa forma, Hi não foi suportada e um resultado inverso ao previsto foi encontrado.

A hipótese de que renda explicaria positivamente a atitude ante o seguro de automóvel (H2) foi confirmada. Isso decorre não apenas pelos motivos levantados por Bond e Stone (2004), mas também porque quanto maior a renda, maior a chance de o participante possuir um automóvel e, portanto, ter necessidade de adquirir um seguro para ele. Foi também constatada que as mulheres possuem uma atitude mais positiva perante esse produto, provavelmente também por serem pessoas mais conservadoras e que buscam segurança (SCHWARTZ, 2005).

Com relação à atitude perante o seguro de vida, o resultado encontrado por Greene (apud SEVERN, I986) foi parcialmente suportado nesta pesquisa ( $\left.\mathrm{H}_{3}\right)$. Segundo o autor, o seguro de vida é um produto que permite expressar a preocupação com os entes queridos e que, portanto, a opinião perante ele não estaria relacionado à idade, ao gênero ou à renda dos indivíduos. No entanto, nesta pesquisa, as mulheres possuem uma atitude mais positiva com relação ao produto, indicando que possivelmente elas têm uma preocupação ou necessidade de expressar com maior evidência sua preocupação para com as pessoas próximas. É possível que essa diferença seja decorrente de diferenças culturais entre essas duas amostras.

O argumento de que esse produto permite expressar a preocupação com as pessoas próximas foi fortalecido pela confirmação de $\mathrm{H}_{4}$, demonstrando que aqueles que têm mais filhos apresentam uma atitude mais elevada com relação ao produto. Dessa forma, a aquisição de um seguro de vida é uma maneira de expressar uma preocupação para com os filhos, afinal geralmente são estes os maiores beneficiários em caso de sinistro. 
$\mathrm{Na}$ hipótese $\mathrm{H}_{5}$, havia a expectativa de que as pessoas com uma renda maior tenderiam a residir em uma área mais visada por ladrões e, portanto, adquiririam seguro residencial com mais freqüência, possuindo uma visão mais positiva em relação a esse produto. Essa crença não foi confirmada, o que nos levou a presumir que as pessoas com renda mais elevada procuram outras formas para proteger seu patrimônio, tais como: segurança privada, sistemas de segurança interna etc.

No entanto, como verificado, identificou-se uma predição positiva de idade em relação à atitude perante o seguro residencial. Esse resultado faz crer que as pessoas mais velhas apresentam uma percepção maior de insegurança para com seus imóveis, talvez por terem vivenciado pessoalmente, ou por meio de terceiros, experiências negativas com suas residências. Com isso, essas pessoas têm uma atitude mais positiva em relação a esse produto.

Ainda com relação ao seguro residencial, o sexo feminino demonstrou possuir uma atitude mais positiva. Isso provavelmente é explicado pelos mesmos motivos dispostos anteriormente, ou seja, as mulheres são mais conversadoras e buscam segurança em maior grau (SCHWARTZ, 2005).

Com relação à previdência complementar, duas hipóteses foram levantadas. A primeira era de que a idade prediria positivamente a atitude perante esse produto. Essa hipótese não foi confirmada. Segundo Murrel (I996), esse produto faz parte de uma realidade mais próxima das pessoas mais velhas e que, por isso, estas dariam uma importância maior a ele. No entanto, o resultado apontou para uma explicação alternativa que age como uma força contrária que ajuda a entender a não-relação encontrada nessa pesquisa. Os participantes da pesquisa de Murrel eram professores de escolas norte-americanas, enquanto que os desta pesquisa são funcionários de uma grande instituição financeira. Conforme dito, estes últimos têm um grande contato com os produtos desta e por isso podem possuir uma opinião diferente, visto que têm elevado grau de conhecimento sobre eles.

Possivelmente, em razão desse grande contato com o produto e suas campanhas publicitárias, os funcionários mais jovens aprendem mais cedo a importância do produto e preocupam-se com antecedência com sua aposentadoria. Além disso, conforme levantado por Marques et al. (2003), por causa das constantes mudanças na previdência oficial no país, as pessoas mais jovens demonstram preocupação antecipada sobre o assunto. Os pontos aqui levantados devem explicar a diferença entre os resultados encontrados.

Já a hipótese $(\mathrm{H} 7)$ de que as mulheres têm uma atitude mais positiva em relação à previdência complementar foi confirmada e coincide com os achados de Murrel (I996) e Joo e Grable (200I). Uma justificativa para tal resultado foi explicada por Joo e Grable (200I) que demonstraram que as mulheres procuram 
mais auxílio profissional, informando-se mais sobre o produto, o que leva a uma atitude mais positiva perante este. Uma vez que a variável nível de informação sobre o produto não foi verificada neste estudo, é possível justificar essa diferença também pela maior expectativa de vida das mulheres, o que as faz ser mais dependentes de planos de aposentadoria. Além disso, no Brasil, elas tendem a aposentar-se antes dos homens.

Apenas uma hipótese foi criada relacionando o título de capitalização (H8), e esta não foi confirmada. Era esperada uma predição significativa da idade ante a atitude, pois, segundo Machauer e Morgner (200I), a atitude dos consumidores perante o risco é mais negativa para aqueles que possuem uma idade mais elevada. De fato, o resultado encontrado por eles é coerente.

Aparentemente, a forma como o título de capitalização é apresentado ao mercado influenciou os resultados, principalmente para a presente amostra, formada por pessoas que têm grande contato com o produto e sua campanha de venda. Por vezes, o produto tem sido apresentado como uma forma de poupança com sorteio ou economia forçada que possibilita sorteios. Essa idéia de poupança passa uma imagem de produto tradicionalista e seguro, sendo mais bem recebido por pessoas de maior idade. Dessa forma, duas imagens antagônicas estão presentes no produto: uma envolvendo tradição e segurança (poupança) e outra envolvendo risco e mudança (sorteio). Com isso, é possível que o produto esteja sendo bem avaliado pelas pessoas mais velhas, mais tradicionalistas (SCHWARTZ, 2005), e também pelos mais jovens que aceitam melhor o risco, levando a uma não-relação entre idade e atitude.

Outras duas importantes variáveis predisseram a atitude perante o título de capitalização: renda e sexo. A primeira possui uma predição negativa perante a atitude, indicando que quanto maior a renda, menor a atitude perante esse produto. Conforme dito anteriormente, o título de capitalização é um produto que oferece rentabilidade abaixo do mercado, apesar da possibilidade de premiação por sorteio. O resultado faz crer que aqueles que possuem renda maior e conseqüentemente mais recursos para investir procuram fazê-lo em outros tipos de aplicação. Possivelmente, aqueles que possuem uma renda mais elevada são os que têm cargos de gerenciamento e que tendem a conhecer mais sobre os produtos financeiros, haja vista que o público-alvo é de pessoas inseridas nesse contexto. Dessa maneira, maior renda aliada ao maior conhecimento sobre a gama de produtos bancários faz com que haja uma atitude negativa ante o título de capitalização, visto que ele é percebido como uma má opção de investimento diante de tantos outros disponíveis.

Os resultados também indicaram que as mulheres têm uma atitude mais positiva do que os homens em relação a esse produto. Esses resultados novamente demonstram o descrito por Schwartz (2005). Segundo o autor, as mulheres 
atribuem maior importância à tradição e conformidade. No entanto, essa possibilidade não pôde ser confirmada, visto que essa variável não foi controlada.

Finalmente, com relação ao consórcio imobiliário, apenas uma hipótese foi criada $\left(\mathrm{H}_{9}\right)$ e confirmada, demonstrando que há uma relação negativa entre idade e atitude perante esse produto. O resultado confirma o proposto por Machauer e Morgner (200I), de que as pessoas mais velhas evitam o risco, mas principalmente leva a crer que estas possuem uma atitude mais negativa em relação ao produto justamente porque percebem que suas chances de desfrutar do prêmio são menores, visto que podem ser contempladas no sorteio apenas quando muito mais idosas. Por serem mais velhos, têm maior urgência em possuir o imóvel.

Outro resultado interessante é a preferência das mulheres pelo consórcio imobiliário. Essa relação novamente aparenta estar ligada à maior importância que as mulheres atribuem aos valores que expressam interesses coletivos (SCHWARTZ, 2005). Dessa forma, o consórcio imobiliário (e a aquisição de um imóvel) é visto como um produto que permite demonstrar essa preocupação, já que a casa provavelmente não será usufruída apenas por aquele que a adquiriu.

Foi encontrada ainda uma relação negativa de escolaridade com a atitude perante o produto. Novamente, esse resultado aparenta estar ligado ao grau de conhecimento sobre os produtos financeiros oferecidos na instituição. É de se esperar que pessoas com maior escolaridade sejam aquelas que possuem melhores cargos na empresa e mais informações sobre os produtos. Com mais informações disponíveis, essas pessoas podem conhecer um produto mais adequado a suas necessidades e que possibilite possuir o imóvel de imediato.

\section{0 contribuições E LIMITAÇões DA PESQUISA}

Uma grande contribuição da presente pesquisa é relativa à possibilidade de aplicação prática dos resultados encontrados. Antes de descrever essas possíveis aplicações, é interessante fazer um breve resumo dos resultados encontrados, já que diversas hipóteses foram levantadas e constatou-se uma quantidade ainda maior de relações. A Tabela 4 apresenta o resumo desses resultados. 
TABELA 4

RESUMO DOS RESULTADOS ENCONTRADOS NO PRESENTE ESTUDO

\begin{tabular}{lcc}
\hline & PREDIÇÃO NEGATIVA & PREDIÇÃO POSITIVA \\
\hline Seguro de automóvel & Idade, renda e mulheres \\
\hline Seguro de vida & Quantidade de filhos e mulheres \\
\hline Seguro residencial & Idade e mulheres \\
\hline Previdência complementar & Renda & Mulheres \\
\hline Título de capitalização & Idade e escolaridade & Mulheres \\
\hline Consórcio imobiliário & Mulheres \\
\hline
\end{tabular}

Fonte: Elaborado pelo autor.

Nessa tabela, constata-se que as mulheres apresentam uma atitude mais positiva para todos os produtos. Segundo Schwartz (2005), as mulheres tendem a ser mais preocupadas com as pessoas próximas e a atribuir maior importância a valores de tradição e conformidade. Isso ajudaria a explicar a maior importância dada por elas a esses produtos, que, apesar de serem oferecidos por instituições financeiras, possibilitam expressar uma preocupação com o outro. Uma vez que diferenças entre gênero não foram tão proeminentes nas poucas pesquisas de temas semelhantes feitas no exterior, esse resultado demonstra ainda uma característica interessante para a cultura brasileira, indicando que em nosso país esses valores são ainda mais importantes para as mulheres. Infelizmente, essa possibilidade não foi diretamente testada nesta pesquisa, fazendo que essa explicação fique apenas como uma hipótese nesse momento.

Conforme dito inicialmente, os resultados aqui encontrados podem ser usados de duas grandes maneiras. Inicialmente, pelos órgãos reguladores que podem exigir critérios mínimos de qualidade com base nas atitudes aqui mensuradas. Por exemplo, os resultados indicam que o título de capitalização tem sido vendido no mercado (e não apenas nessa instituição) de forma incoerente com as reais características do produto. Esta pesquisa indica a necessidade de intervenção para garantir regras mínimas de qualidade. Além dos órgãos reguladores, as próprias instituições financeiras podem aplicar esses resultados gerencialmente ou junto aos seus clientes finais. Uma possível aplicação seria a alocação de mulheres para venderem esses produtos, uma vez que elas demonstraram uma atitude mais positiva, o que poderia facilitar a venda. Outra maneira seria reali- 
zar uma pesquisa semelhante no grande público e com isso guiar estratégias de marketing para atrair ou manter os consumidores. Por exemplo, para produtos em que a renda foi o fator mais relevante, propagandas que usam argumentos racionais podem ser mais eficientes, enquanto, para os produtos em que o gênero (e possivelmente diferença em valores pessoais) é mais importante, uma propaganda embasada em argumentos afetivos pode ser mais eficiente (CERVELLON; DUBÉ, 2002).

Uma importante contribuição desta pesquisa advém do fato de que o instrumento desenvolvido pode ser aplicado em outros contextos em razão de seu caráter generalista. Conforme pode ser visto na redação dos itens que permaneceram em sua versão final, o questionário não é voltado para um produto específico ou mesmo para uma categoria específica de produtos. Com isso, esta pesquisa apresenta um questionário válido que pode ser usado na avaliação da atitude perante os mais diversos produtos.

Por fim, uma importante contribuição desta pesquisa é a publicação de resultados que não eram previstos inicialmente, como foi o caso de Hi. Essa prática é pouco comum, haja vista que os autores têm receio de publicar resultados que suportam a hipótese nula ou podem colocar o método da pesquisa em xeque. Muitas vezes, esse receio é contraproducente, já que inibe uma das principais ferramentas que garantem a confiabilidade do conhecimento científico que é a replicação. Além disso, esses resultados demonstram também que o processo entre atitude e dados sociodemográficos funciona de maneira diferente para a realidade brasileira, ao menos no que tange aos funcionários que vendem esses produtos. Isso indica uma diferença cultural interessante e ressalta que pesquisas realizadas no exterior devem ser aplicadas com muito cuidado na realidade nacional.

As limitações da presente pesquisa são basicamente oriundas de problemas metodológicos.

Quanto às limitações metodológicas, um primeiro ponto a ser ressaltado é relativo à estratégia de aplicação adotada. Uma vez que os consultores possuíam liberdade para aplicar os questionários, entrevistando qualquer funcionário lotado nos pontos-de-venda, é possível que eles tenham escolhidos aqueles com quem tinham maior contato e amizade ou ainda os que provavelmente iriam avaliar positivamente o produto. No treinamento destes, solicitou-se apenas que fossem aplicados questionários preferencialmente junto aos funcionários que vendem esses produtos, e todos deveriam estar lotados no ponto-de-venda. Como não foi controlada essa variável, é possível que haja uma influência causada pelos próprios consultores.

Outro problema é a não-uniformização do ambiente de aplicação. De fato há uma relativa uniformização, visto que todos os questionários foram aplicados em 
pontos-de-venda, porém a pesquisa foi realizada em todo o Brasil e em pontosde-venda de todas as regiões geográficas de cidades de pequeno, médio e grande portes. Sendo assim, é coerente imaginar que haja uma diferença na realidade de cada um desses pontos-de-venda. Essa diferença de realidade resulta em um ambiente de aplicação diferente, ou seja, algumas pessoas podem ter respondido ao questionário em um momento de grande estresse, almoçando ou no fim do expediente após uma cansativa jornada de trabalho. Outras podem ter respondido logo quando chegaram ou durante o expediente, visto que existem pontos-devenda mais tranqüilos do que outros. Essa diferença na ambientação, também difícil de ser controlada, pode levar a algum viés nas respostas.

A amostra também é um fator limitador da presente pesquisa. A quantidade de participantes demonstrou-se adequada para as análises. No entanto, por ter sido realizada apenas por funcionários da instituição financeira, a pesquisa torna-se naturalmente enviesada. Esses participantes possuem um elevado grau de contato com os produtos avaliados. Grande parte deles vende os produtos ou já os vendeu, sendo assim, detém um grande conhecimento sobre eles e até mesmo envolvimento. Esses vieses ajudam a explicar o porquê de a média do escore de atitude perante esses produtos ser tão elevada, estando todos entre 3,25 e 4,I2 (em uma escala que vai de I a 5), com exceção do título de capitalização, que teve média de 2,31. Com essa possível valorização exagerada dos produtos, algumas relações entre valores e atitudes podem não ocorrer em outras amostras.

Um terceiro limitador refere-se a um dos instrumentos utilizados na pesquisa. Apesar de ter sido criado com base em uma metodologia coerente com os parâmetros atuais, a escala de atitude perante produtos bancários foi criada para esta pesquisa, tendo sido pouco aplicada. No entanto, conforme pôde ser visto nesta pesquisa, os alfas da escala são bastante confiáveis.

Por fim, é interessante notar que a pesquisa leva a crer que as variáveis demográficas são pouco importantes para prever atitude. Outras variáveis psicológicas devem ser mais relevantes, como valores pessoais, normas sociais e nível de informação sobre o produto. Infelizmente, essas variáveis não foram consideradas neste momento e, portanto, demonstram uma limitação, haja vista que importantes variáveis explicativas não foram mensuradas. 


\section{APÊNDICE I}

\begin{tabular}{|c|c|c|c|c|c|c|}
\hline & $\begin{array}{l}\text { SEGURO } \\
\text { DE VIDA }\end{array}$ & $\begin{array}{l}\text { SEGURO } \\
\text { DE AUTO- } \\
\text { MÓVEL }\end{array}$ & $\begin{array}{l}\text { SEGURO } \\
\text { RESIDEN- } \\
\text { CIAL }\end{array}$ & $\begin{array}{l}\text { PREVIDÊNCIA } \\
\text { COMPLEMEN- } \\
\text { TAR }\end{array}$ & $\begin{array}{l}\text { TÍTULO DE } \\
\text { CAPITALI- } \\
\text { ZAÇÃO }\end{array}$ & $\begin{array}{l}\text { CONSÓRCIO } \\
\text { IMOBILIÁRIO }\end{array}$ \\
\hline \multicolumn{7}{|l|}{$\begin{array}{l}\text { 1. Tenho interesse em adquirir } \\
\text { esse produto. }\end{array}$} \\
\hline \multicolumn{7}{|l|}{$\begin{array}{l}\text { 2. Acho muito importante } \\
\text { possuir esse produto. }\end{array}$} \\
\hline \multicolumn{7}{|l|}{ 3. Gosto desse produto. } \\
\hline \multicolumn{7}{|l|}{$\begin{array}{l}\text { 4. A pessoa que adquire esse } \\
\text { produto possui um futuro } \\
\text { mais promissor. }\end{array}$} \\
\hline \multicolumn{7}{|l|}{$\begin{array}{l}\text { 5. Todos deveriam possuir esse } \\
\text { produto. }\end{array}$} \\
\hline \multicolumn{7}{|l|}{$\begin{array}{l}\text { 6. Traz satisfação pessoal } \\
\text { possuir esse produto. }\end{array}$} \\
\hline \multicolumn{7}{|l|}{$\begin{array}{l}\text { 7. Este produto oferece } \\
\text { poucos benefícios àquele } \\
\text { que o possui. }\end{array}$} \\
\hline \multicolumn{7}{|l|}{$\begin{array}{l}\text { 8. Esse é um produto } \\
\text { excelente. }\end{array}$} \\
\hline \multicolumn{7}{|l|}{$\begin{array}{l}\text { 9. A pessoa que possui esse } \\
\text { produto jogou seu dinheiro } \\
\text { fora. }\end{array}$} \\
\hline \multicolumn{7}{|l|}{$\begin{array}{l}\text { 10. Esse produto é para quem } \\
\text { pensa em longo prazo. }\end{array}$} \\
\hline \multicolumn{7}{|l|}{$\begin{array}{l}\text { 11. Esse produto só serve para } \\
\text { dar dinheiro às instituições } \\
\text { financeiras. }\end{array}$} \\
\hline $\begin{array}{l}\text { 12. Esse produto diminui os } \\
\text { riscos de prejuízo em longo } \\
\text { prazo. }\end{array}$ & & & & & & \\
\hline
\end{tabular}




\section{APÊNDICE I (CONTINUAÇ̃̃o)}

\begin{tabular}{|c|c|c|c|c|c|c|}
\hline & $\begin{array}{l}\text { SEGURO } \\
\text { DE VIDA }\end{array}$ & $\begin{array}{l}\text { SEGURO } \\
\text { DE AUTO- } \\
\text { MÓVEL }\end{array}$ & $\begin{array}{l}\text { SEGURO } \\
\text { RESIDEN- } \\
\text { CIAL }\end{array}$ & $\begin{array}{l}\text { PREVIDÊNCIA } \\
\text { COMPLEMEN- } \\
\text { TAR }\end{array}$ & $\begin{array}{l}\text { TíTULO DE } \\
\text { CAPITALI- } \\
\text { ZAÇÃO }\end{array}$ & $\begin{array}{l}\text { CONSÓRCIO } \\
\text { IMOBILIÁRIO }\end{array}$ \\
\hline $\begin{array}{l}\text { 13. Esse produto oferece } \\
\text { maior bem-estar para meu } \\
\text { cotidiano. }\end{array}$ & & & & & & \\
\hline $\begin{array}{l}\text { 14. Acredito que com esse } \\
\text { produto as empresas } \\
\text { enganam os clientes. }\end{array}$ & & & & & & \\
\hline $\begin{array}{l}\text { 15. Esse produto não traz } \\
\text { segurança (tranqüilidade) a } \\
\text { quem o possui. }\end{array}$ & & & & & & \\
\hline $\begin{array}{l}\text { 16. A pessoa que possui esse } \\
\text { produto demonstra status } \\
\text { social. }\end{array}$ & & & & & & \\
\hline $\begin{array}{l}\text { 17. Eu recomendaria esse } \\
\text { produto para meus amigos. }\end{array}$ & & & & & & \\
\hline $\begin{array}{l}\text { 18. As regras desse produto são } \\
\text { muito inconstantes. }\end{array}$ & & & & & & \\
\hline $\begin{array}{l}\text { 19. Não confio nas empresas } \\
\text { que oferecem esse produto. }\end{array}$ & & & & & & \\
\hline $\begin{array}{l}\text { 20. Esse é um produto } \\
\text { adequado para as } \\
\text { necessidades da minha } \\
\text { vida. }\end{array}$ & & & & & & \\
\hline $\begin{array}{l}\text { 21. Esse é o pior produto } \\
\text { oferecido por uma } \\
\text { instituição financeira. }\end{array}$ & & & & & & \\
\hline $\begin{array}{l}\text { 22. Nos contratos desse } \\
\text { produto sempre me sinto } \\
\text { enganado(a). }\end{array}$ & & & & & & \\
\hline
\end{tabular}




\section{REFERÊNCIAS}

AJZEN, I.; FISHBEIN, M. Understanding attitudes and predicting social behaviour. Englewood Cliffs, NJ: Prentice-Hall, ig8o.

ALLPORT, G. W. Attitudes. In : MUSCHISON, C. (Ed.). Handbook of social psychology. Worcercester, MA: Clark University Press, I935.

BOND, A.; STONE, M. How the automotive insurance claims experience affects custumer retention. Journal of Financial Services Marketing, v. 9, n. 2, p. 160-173, 2004.

CATO, F. W. Insurance and brokerages rated among America's least trusted! Financial Services Advisor, v. I45, n. 5, p. 26-3I, 2002.

CERVELLON, M.C.; DUBÉ, L. Assessing the cross-cultural applicability of affective and cognitive components of attitudes. Journal of Cross Cultural Psychology, v. 33, n. 3, p. 346-357. 2002.

FAZIO, R. H. et al. On the automatic activation of attitudes. Journal of Personality and Social Psychology, v. 50, p. 229-238. I986.

FISHBEIN, M. The relationships between beliefs, attitudes and behavior. New York: Academic Press. I966.

FISHBEIN, M.; AJZEN, I. Belief, attitude, intention and behaviour: an introduction to theory and research. Reading, MA: Addison-Wesley. I975.

GREENE, M. R. Insurance mindedness-implications for insurance theory. The Journal of Risk and Insurance, p. 27-38, 1964.

GREGORY, G. D. et al. Attitude functions in consumer research: comparing value-attitude relations in individualist and collectivist cultures. Journal of Business Research, v. 55, p. 933-942, 2002. JOO, S.-H.; GRABLE, J. E. Factors associated with seeking and using professional retirement-planning help. Family and Consumer Sciences Research Journal, v. 30, n. I, p. 37-63, 200 I.

MACHAUER, A.; MORGNER, S. Segmentation of bank customers by expected benefits and attitudes. International Journal of Bank Marketing, v. I9, n. I, p. 6-17, 200 I.

MAIO, G. R.; OLSON, J. M. Relations Between values, attitudes, and behavioral intentions: the moderating role of attitude function. Journal of Experimental Social Psychology, v. 3I, p. 266-285, I995. MARQUES, M. R. et al. Previdência social brasileira - um balanço da reforma. São Paulo em Perspectiva, v. I7, n. I, p. III-I2I, 2003.

MURREL, H. R. Principals attitudes toward early retirement incentive plans and their releationship to selected demographic variables. I996. Dissertation (Master's Degree)-Mississippi State University, Mississippi, I996.

OSGOOD, C. E. et al. The measurement of meaning. Urbana: University of Illinois Press, 1967.

PETTY, R. E. Attitude change. In: TESSER, A. (Ed.). Advanced social psychology. New York: MacGrawHill, I995.

RODRIGUES, A. Psicologia social. Petrópolis: Vozes, I972.

SCHWARTZ, S. H. Validade e aplicabilidade da teoria de valores. In: TAMAYO, A.; PORTO, J. B. (Org.). Valores e comportamento nas organizações. Petrópolis: Vozes, 2005.

SEVERN, R. Preference for atributes of life insurance: a conjoint measurement approach. I986. Dissertation (Master's Degree)-University of Nebraska, Nebraska, I986.

WHITLEY, B. E. Principles of research in behavioral science. New York: McGraw Hill, $200 \mathrm{I}$.

WILLCOX, T. L.; HARRIS, P. A. The effect of intense selling of premium-loan insurance on the attitudes of college students toward the insurance industry. The Journal of Risk and Insurance Issues and Practices, p. 39-51, 1980. 